Their prohibitive cost is beyond the means of most small health centres and virtually all households (current price $£ 685.91$ including VAT for the Model 20 Egnell electric breast pump; Eschmann Bros and Walsh Ltd, Sussex). Yet it is in poorer communities that the potential need for such devices may be greatest.

The Bristol breast pump is simple both in design and in operation and should cost well under $£ 15$ if mass produced. It is easily sterilised and requires no maintenance. It affords the mother the freedom to select a comfortable suction pressure and to express milk at her own rate. Such a pump may provide a means for initiating, maintaining, or extending the lactational period in mothers who might otherwise resort to artificial infant formulas.

I thank the staff on ward 76 of Bristol Maternity Hospital, Mr R T Batchen for his indispensable glassblowing skills, Dr V M Sponsel for testing prototypes, and Gary $M$ James for the illustration.

This work has been supported by La Leche League International.

1 Vorherr H. Human lactation and breast feeding. In: Lactation: a comprehensive treatise. Vol 4. New York: Academic Press, 1978.

${ }^{2}$ Cunningham A. Morbidity in breast-fed and artificially fed infants. $\mathcal{f}$ Pediatr $1979 ; 95: 685-9$.

${ }^{3}$ Welsh J, May J. Anti-infective properties of breast milk. $\mathcal{F}$ Pediatr 1979 94:1-9.

${ }^{4}$ Klaus M, Kennel J. Maternal infant bonding. St Louis: C V Mosby Co, 1976.

${ }^{5}$ Gallenkamp. Scientific catalogue 1980. London: Gallenkamp, 1980:562-3.

(Accepted 17 fanuary 1983)

Department of Obstetrics and Gynaecology, University of Bristol Medical School, Bristol BS2 8BJ

WILLIAM E SPONSEL, BSC, clinical medical student

Correspondence to: 40 St John's Road, Clifton, Bristol BS8 2HG.

\section{Evidence that disopyramide does not interact with warfarin}

Haworth and Burroughs reported that disopyramide interacts with warfarin. ${ }^{1}$ Their observation was based on a single case where disopyramide was discontinued in a hypotensive patient because of its potential negative inotropic effect. A good clinical response occurred over 24 hours followed by a decreasing prothrombin time requiring incremental doses of warfarin. They concluded that the apparent interaction between disopyramide and warfarin might be a competitive phenomenon at the receptor site. Our findings refute their evidence.

\section{Present study and results}

We studied the doses of dicoumarol or warfarin in seven patients before and after conversion of atrial fibrillation (table). Two of the patients received dicoumarol and five warfarin. Quinidine sulphate was given to four of the patients (400 mg thrice daily) as an antiarrhythmic agent, while three-al receiving warfarin-were given disopyramide $(200 \mathrm{mg}$ thrice daily). With this treatment some patients regained sinus rhythm, and in the others sinus rhythm was regained after DC conversion. All except one of the patients needed a small increase in the weekly anticoagulant dose; the remaining patient had an increase in thrombotest value (table). (The dose was expressed as the mean number of tablets used weekly during five weeks before or five weeks after conversion. The dosage of oral anticoagulant drug was prescribed so that the thrombotest value was within therapeutic limits.)
After conversion of atrial fibrillation and start of quinidine or disopyramide an increase of about $10 \%$ was needed in the dose of dicoumarol or warfarin to keep the thrombotest value within the therapeutic range. Although the number of patients was small the same increase in anticoagulant dosage was required when patients were treated with either dicoumarol or warfarin in combination with quinidine sulphate or disopyramide.

\section{Comment}

Warfarin and other anticoagulant agents such as dicoumarol interact with a large variety of drugs. Both an increase and a decrease in anticoagulant action may be observed clinically. Only Haworth and Burroughs ${ }^{1}$ have reported an interaction between disopyramide and warfarin. In contrast with other reports, ${ }^{2}$ we found a decreased anticoagulant effect when dicoumarol or warfarin was combined with quinidine. A decreased effect was also observed in two of the three patients receiving warfarin when disopyramide was added.

The mechanism for the observed need for an increase in anticoagulant dosage after conversion of atrial fibrillation to sinus rhythm is unknown. Nevertheless, that patients treated with quinidine or disopyramide showed the same decrease in anticoagulant effect after conversion suggests that haemodynamic factors might be implicated. In sinus rhythm regular atrial contractions might contribute to increased cardiac output and increased liver blood flow. This might result in an enhanced production of prothrombin and other coagulation factors, requiring a higher anticoagulant regimen. The patient described by Haworth and Burroughs was, in fact, initially hypotensive but recovered after discontinuation of the disopyramide. Thus their patient initially had a low cardiac output that later returned to normal, which also might explain the observed decrease in prothrombin time.

${ }^{1}$ Haworth E, Burroughs AR. Disopyramide and warfarin interaction. $\mathrm{Br}$ Med $\mathcal{F} 1977$;ii :866-7.

${ }^{2}$ Koch-Weser J. Quinidine-induced hypoprothrombinemic hemorrhage in patients on chronic warfarin therapy. Ann Intern Med 1968;68:511-7.

(Accepted 12 fanuary 1983)

Karolinska Hospital, S-104 01 Stockholm, Sweden

CHRISTER SYLVÉN, MD, department of medicine PER ANDERSON, MD, department of clinical pharmacology

Correspondence to: Dr Christer Sylvén.

\section{Effect of doxapram on heavy sedation produced by intravenous diazepam}

Diazepam is widely used to provide sedation during endoscopy, biopsy procedures, and minor surgery. Given intravenously it may cause excessive sedation and ventilatory depression. There is no specific antidote. We carried out a randomised controlled trial of the effects of doxapram in patients heavily sedated with intravenous diazepam.

\section{Patients, methods, and results}

We studied 115 patients undergoing gastroduodenoscopy with intravenous diazepam sedation; no other sedation or premedication was used. None of

Anticoagulant treatment before and after DC conversion of atrial fibrillation (dose given as mean weekly number of tablets (dicoumarol $50 \mathrm{mg}$, warfarin $2.5 \mathrm{mg}$ )), mean weekly thrombotest result (\%), and antiarrhythmic treatment

\begin{tabular}{|c|c|c|c|c|c|c|c|c|c|}
\hline \multirow{2}{*}{$\begin{array}{l}\text { Case } \\
\text { No }\end{array}$} & \multirow{2}{*}{$\underset{\text { (years) }}{\text { Age }}$} & \multirow[b]{2}{*}{ Anticoagulant } & \multicolumn{3}{|c|}{ Mean weekly dose (No of tablets) } & \multicolumn{3}{|c|}{ Mean weekly thrombotest result ( $\%$ ) } & \multirow{2}{*}{$\begin{array}{l}\text {-Antiarrhythmic } \\
\text { treatment }\end{array}$} \\
\hline & & & Before & $p<0.01$ & After & Before & NS & After & \\
\hline $\begin{array}{l}1 \\
2 \\
3 \\
4 \\
5 \\
6 \\
7\end{array}$ & $\begin{array}{l}62 \\
67 \\
49 \\
60 \\
63 \\
70 \\
62\end{array}$ & $\begin{array}{l}\text { Dicoumarol } \\
\text { Dicoumarol } \\
\text { Warfarin } \\
\text { Warfarin } \\
\text { Warfarin } \\
\text { Warfarin } \\
\text { Warfarin }\end{array}$ & $\begin{array}{r}6 \cdot 0 \\
10.5 \\
10.5 \\
13 \cdot 0 \\
14 \cdot 0 \\
14 \cdot 5 \\
13.0\end{array}$ & & $\begin{array}{r}7 \cdot 0 \\
13 \cdot 0 \\
12 \cdot 0 \\
14 \cdot 0 \\
14 \cdot 0 \\
16 \cdot 0 \\
14 \cdot 0\end{array}$ & $\begin{array}{rl}10 & +5 \\
10 & +2 \\
7 & 3 \\
10 & 3 \\
8 & 3 \\
11 & 2 \\
9 & 6\end{array}$ & & $\begin{array}{ll}10 & 4 \\
10 & 2 \\
13 & 4 \\
9 & 2 \\
12 & 1 \\
14 & 2 \\
11 & 3\end{array}$ & $\begin{array}{l}\text { Quinidine } \\
\text { Quinidine } \\
\text { Quinidine } \\
\text { Quinidine } \\
\text { Disopyramide } \\
\text { Disopyramide } \\
\text { Disopyramide }\end{array}$ \\
\hline
\end{tabular}


the patients had hypertension (diastolic blood pressure $>95 \mathrm{~mm} \mathrm{Hg}$ ), ischaemic heart disease, asthma, respiratory failure, or thyrotoxicosis or was alcoholic. All patients yielded normal results to liver function tests. All gave informed written consent to the study, which was approved by the hospital research committee.

Before endoscopy respiratory rate and blood pressure were recorded and expired minute ventilation measured with a Wright's respirometer attached to a closely fitting anaesthetic face mask. The orientation and cognitive function of each patient were tested by standardised questions regarding place and time, and simple mental arithmetic; the patient's overall state of alertness was evaluated and recorded on a $10 \mathrm{~cm}$ horizontal visual analogue scale ranging from totally unresponsive $(0 \mathrm{~cm})$ to fully alert $(10 \mathrm{~cm})$. All evaluations were made by the same physician and sealed in separate envelopes to prevent comparisons during the study.

Another physician administered diazepam by slow intravenous injection until sedation and relaxation were produced as indicated by drooping of the patient's eyelids, dysarthria, generalised muscle relaxation, and ability to swallow the gastroscope. After endoscopy measurements of alertness, ventilation, and blood pressure were repeated. Each patient was then randomly assigned to receive by bolus intravenous injection either $100 \mathrm{mg}$ doxapram or an identical placebo; assessments were repeated five, 60 , and 120 minutes later.

Data were analysed by paired $t$ test, $\chi^{2}$ test, or Fisher's exact test.

Before diazepam all 115 patients were orientated and 113 could make a satisfactory attempt at mental arithmetic. After diazepam 24 became unexpectedly heavily sedated (visual analogue scale $<5 \mathrm{~cm}$ ). There were no significant differences in dose of diazepam (mean $26.0 \mathrm{mg}$ ), age, weight, height, liver function, or concurrent medication between patients who became heavily or lightly sedated.

Of the 24 heavily sedated patients, 13 received doxapram and 11 placebo. There was a highly significant improvement compared with placebo five minutes after doxapram was given: the number of patients orientated increased from three to nine $(p<0.0001)$, the number able to attempt mental arithmetic from three to $10(\mathrm{p}<0.0001)$, and the mean visual analogue score from 2 to $7 \mathrm{~cm}(p<0.001)$. None of the measurements after placebo changed. A mean increase in ventilation of $1.71 / \mathrm{min}(\mathrm{p}<0.001)$ occurred in patients who received doxapram, but there was no change in ventilation in those given placebo.

Sixty minutes after injection of doxapram ventilation had fallen to values seen before injection and was similar in heavily sedated patients who had received doxapram and those who had received placebo. However, the level of alertness of the heavily sedated patients who had received doxapram did not fall (figure); the proportion orientated, the number able to do arithmetic, and the mean visual analogue score were the same as at five minutes. During the elapsed time the alertness of the placebo-treated patients had increased, so the difference between the two groups was not significant. After 120 minutes there were no differences.

No potentially serious side effects occurred. All patients who received doxapram showed a small rise in systolic blood pressure (mean rise $24 \mathrm{~mm} \mathrm{Hg}$ ) but no change in heart rate. Eight patients complained of feeling hot and sweaty; they were all lightly sedated. In no patient did doxapram interfere with the short term memory loss produced by intravenous diazepam or induce convulsions.

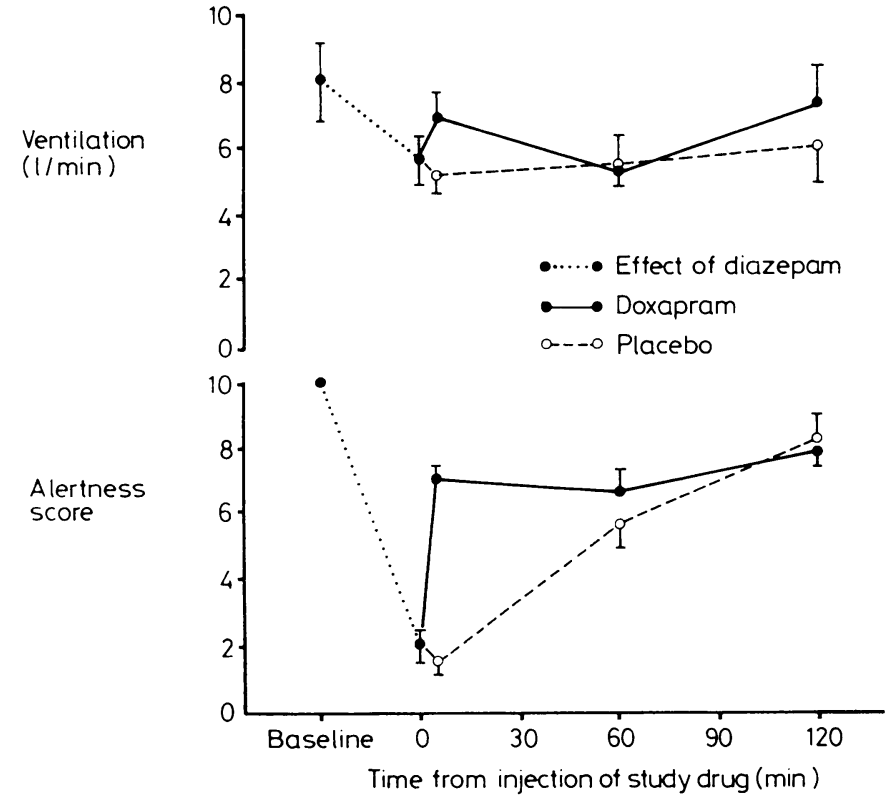

Effect of doxapram on alertness and ventilation of patients heavily sedated with diazepam (mean $\left.\_S E M\right)$. Baseline measurements were taken before endoscopy and administration of diazepam. Time 0 was after endoscopy, showing effect of diazepam immediately before patient received study drug (doxapram or placebo).

\section{Comment}

Doxapram is both a peripheral chemoreceptor agonist and central neuronal stimulant ${ }^{12}$; it speeds recovery from general anaesthesia ${ }^{34}$ and reverses opiate induced ventilatory depression.

Roughly one fifth of patients in this study who received intravenous diazepam became unexpectedly and unpredictably heavily sedated; this randomised controlled trial shows that doxapram effectively and safely reverses this heavy sedation.

We thank Sister Joy Banks and the staff of the diagnostic unit; $\mathrm{Mr} \mathrm{C}$ Jones for providing doxapram, placebo, and the statistical analysis; and $\mathrm{Dr}$ M Craven for editorial help.

1 Hirsh K, Wang SC. Selective stimulating action of doxapram compared to pentylenetrorazol. I Pharmacol Exp Ther 1974;189:1-11.

2 Mitchell RA, Herbert DA. Potencies of doxapram and hypoxia in stimulating carotid-body chemoreceptors and ventilation in anaesthetized cats. Anesthesiology 1975;42:559-66.

${ }^{3}$ Robertson GS, MacGregor DM, Jones CJ. Evaluation of doxapram for arousal from general anaesthesia in outpatients. Br f Anaesth 1977;49: 133-9.

- Gupta PK, Dundee JW. Hastening of arousal after general anaesthesia with doxapram hydrochloride. Br J Anaesth 1973;45:493-6.

${ }^{5}$ Ramamurthy S, Steer NS, Wirrie A. Doxapram antagonism of meperidine induced respiratory depression. Anesth Analg (Cleve) 1975;54:352-6.

(Accepted 20 fanuary 1983)

Diagnostic Unit, Royal Unit Hospital, Bath

CHRISTOPHER J ALLEN, MRCP, medical registrar

KENNETH R GOUGH, MD, FRCP, consultant physician

Correspondence to: Dr Christopher J Allen, MRC research fellow, Ambrose Cardio-Respiratory Unit, McMaster University Medical Centre, 1200 Main Street West, Hamilton, Ontario, Canada.

Reprint requests to: Dr K R Gough, Royal United Hospital, Combe Park, Bath, Avon.

\section{Trimethoprim resistance in Gram negative urinary pathogens}

Trimethoprim has been available for use alone in Great Britain since 1979. As there is in vitro evidence that the presence of a sulphonamide inhibits the development of resistance to this agent ${ }^{1}$ it is important that observations on the level of resistance in clinical isolates should be made. We have kept figures for the normally susceptible Gram negative urinary pathogens isolated in our laboratory during the month of October for the past five years.

\section{Methods and results}

Sensitivity testing, whether primary or secondary, was performed by a modified Stokes method, using Escherichia coli NCTC 10418 as the control organism. Discs containing $100 \mu \mathrm{g}$ sulphafurazole and $25 \mu \mathrm{g}$ co-trimoxazole (23.5 $\mu \mathrm{g}$ sulphamethoxazole, $1.5 \mu \mathrm{g}$ trimethoprim) were included in the agents tested. Zones not more than $3 \mathrm{~mm}$ smaller than the control were interpreted as sensitive, those of at least $3 \mathrm{~mm}$ radius but more than $3 \mathrm{~mm}$ smaller than the control as moderately resistant, and those of less than $3 \mathrm{~mm}$ radius as resistant. Tests giving equivocal results or "clouded" zones (especially those with too heavy an inoculum) were repeated; since 1979 organisms showing borderline zones with co-trimoxazole have been retested with a $2.5 \mu \mathrm{g}$ trimethoprim disc. All organisms found to be sensitive to sulphonamide but apparently resistant to co-trimoxazole have also been retested with a trimethoprim disc. There has been no change in this methodology over the study period.

Sensitivity tests were performed only when the isolates were considered to be clinically relevant; thus the figures do not include isolates from bag specimens from babies, or, except rarely, mixed isolates or isolates from patients with long term indwelling catheters.

Moderately resistant and resistant isolates were not separated in the records before 1981; the figures were kept separately for 1981 and 1982 . In 1981 and 1982 the figures for hospital (inpatient and outpatient) and general practitioner patients were also analysed separately.

The table shows the percentage of isolates considered to be resistant to trimethoprim over the study period.

None of the organisms that were retested with a trimethoprim disc were found to be sensitive. During 1981 only four of 100 resistant isolates and during 1982 only 22 of 169 resistant isolates were moderately resistant.

mo

\section{.} , 